\title{
Weak definites as a form of definiteness: experimental investigations
}

Greg Carlson, Natalie Klein, Whitney Gegg-Harrison and Michael Tanenhaus

\section{OpenEdition}

\section{Journals}

Electronic version

URL: http://journals.openedition.org/rlv/2158

DOI: $10.4000 /$ rlv.2158

ISSN: 1958-9239

Publisher

Presses universitaires de Vincennes

\section{Printed version}

Date of publication: 1 December 2013

Number of pages: 11-32

ISBN: 978-2-84292-397-6

ISSN: 0986-6124

Electronic reference

Greg Carlson, Natalie Klein, Whitney Gegg-Harrison and Michael Tanenhaus, «Weak definites as a form of definiteness: experimental investigations », Recherches linguistiques de Vincennes [Online] 42 | 2013, Online since 01 March 2016, connection on 20 April 2019. URL : http:// journals.openedition.org/rlv/2158; DOI : 10.4000/rlv.2158 
Recherches linguistiques de Vincennes 42 - 2013 - p. 11-32

\author{
Greg CARLSON, Natalie KLEIN, \\ Whitney GEGG-HARRISON, and Michael TANENHAUS \\ University of Rochester
}

\title{
WEAK DEFINITES AS A FORM OF DEFINITENESS: EXPERIMENTAL INVESTIGATIONS
}

\begin{abstract}
Definite noun phrases typically refer to entities that are uniquely identifiable in the speaker and addressee's common ground. However, some definite noun phrases (e.g. the hospital in Mary had to go the hospital and John did too) seem to violate uniqueness. We discuss a series of experiments that seek to understand some of the properties of this class of definites. We consider most carefully the hypothesis that these "weak definite" interpretations arise in implicitly "incorporated" constructions, attempting to provide a sketch of this hypothesis' motivation and potential consequences. In our experiments we found that compared to regular definites, the weak definites need not refer uniquely, and readily trigger semantically enriched readings that compete effectively with normal inferences one might draw from a sentence. Perhaps the most surprising finding in the experiments is that nouns that could occur as weak definites, also seemed to retain some of these "weak" properties even when expressed as indefinites. We try and make sense of this within the "incorporation" framework.
\end{abstract}

\section{KEYWORDS}

Definite article, incorporation, weak definites, weak reference, semantics, pragmatics. 


\section{Introduction ${ }^{1}$}

It has been known for some time that there are at least two forms of definiteness. Ebert (1971) discusses Fering, a Frisian dialect in which the definite article has two forms, what she calls the "A-article" and the "D-article".

$\begin{array}{lcccc} & \text { masc.sg. } & \text { fem.sg. } & \text { neut.sg. } & \text { pl. } \\ \text { A-article: } & \text { a } & \text { at } & \text { at } & \text { a } \\ \text { D-article: } & \text { di } & \text { det } & \text { det } & \text { dön }\end{array}$

The two articles are used in different ways. Very roughly, the a-article is employed where something like the object is taken as already known, as in the case of proper names, generics, or uniquely descriptive noun phrases; the darticle is deictic in nature and used mostly in the case of discourse anaphora, and may be approximately characterized as "discourse familiarity." Examples (1) and (2) are from Fering:

(1) (D-article) Oki hee jister an hingst keeft. Di hingst leept üüb stuuven. 'Yesterday Oki bought a horse. The horse is in the paddock.'

(2) (A-article) Hi skraft me a lachter hun.

'He writes with the left hand.' (Ebert 1971)

This brief characterization is imprecise, of course but this and subsequent work on other Germanic dialects with differing definite articles (e.g. Hartmann 1982) establishes that at least two classes of definites can be identified.

Until about the mid-1990's, most of the work on definiteness focused on data in which the two different roles of definites were not clearly distinguished, the work of Löbner (1985) approaching the territory. However, it was Poesio (1994) who noted instances of noun phrases in which the context provided within the NP itself served to justify the use of the definite article, as in the example:

(3) John got these data from the student of a linguist.

Poesio dubbed such instances "weak" in interpretation, and so the notion of a "weak definite". Barker (2005) focused on a subclass of Poesio's weak examples, giving an analysis of such cases as:

(4) Look for the huge whale on the side of the building.

1. This paper is based on Klein et al. (2013). Readers will find more details of the experiments and their results described there. We wish to thank Claire Beyssade and an anonymous referee for comments that sharpened and improved this paper markedly. Work on this project was supported by NIH grant HD27206. 
We assume a building has more than one side, yet the definite here is felicitous. The notion of "weak" definiteness is taken up in comprehensively in Schwarz (2009).

Carlson and Sussman (2005) and Carlson et al. (2006) argue that there is a further class of "weak" definites to be recognized which likewise seem to defy uniqueness. Take the example of the hospital in (3), and contrast it with "the arena" in the following dialogue:

(5) Sarah: Where did they take the hurricane victims?

Otto: To the arena/to the hospital.

Sarah: Which one?

Otto: I don't know.

Otto's answer, I don't know, is not felicitous if one uses the arena; in this case Otto's use of a definite noun phrase suggests that he is referring to a particular arena that has already been established as a part of the interlocutors' common ground. However, the same answer, I don't know, which seems an odd response following a typical definite like the arena, is natural when the antecedent is instead the hospital. The intuition is that despite having the form of a definite noun phrase, the hospital need not introduce or refer to a uniquely identifiable referent, though, of course, this standard referential reading may also be available.

It turns out that there is a class of such definites in English, as in "read the newspaper", "check the calendar", "take the train", and "(be) at the beach". However, this class is not the same as a NP with a definite article. Such cases have a cluster of properties associated with them. For example in (6a) below, although radio allows a weak interpretation in a definite noun phrase, this is not necessarily true of related nouns like record in example (6b):

a. Benedict listened to the radio, and Tracy did too.

b. Benedict listened to the record, and Tracy did too.

Example (6a) allows a weak interpretation in which Benedict and Tracy listened to different radios, but (6b) does not. While it seems plausible for Tracy to have listened to a different copy of the same record (i.e., a different token of the same album), it is not consistent with the sentence for Tracy to have listened to a record with different content; if Benedict had been listening to some recording of Blood on the Tracks, Tracy could not have been listening to Modern Times.

Although weak definite interpretations in English are lexically restricted, the noun is not the sole determinant of a weak interpretation. Restrictive modification, as with the adjective in (7), typically forces a regular definite interpretation:

(7) Benedict listened to the new radio and Tracy did too. 
Modifying radio with new emphasizes one property of a referent, which sets this radio apart from other possible radios. Thus the modified phrase supports only a typical definite interpretation.

Weak definites are further restricted by the need to co-occur with, or be "governed by," certain other lexical items - verbs and prepositions. For example, look at the radio or park near the hospital do not have weak readings despite the fact that the noun (radio, hospital) under other circumstances allows a weak reading.

The lexical restrictions and co-occurrence sensitivity of weak definite noun phrases raises the possibility that they are idioms, where a closed set of words and phrases lead to a richer meaning than their literal components would suggest. While we take "idioms" to be a part of a gradient class of collocations (Nunberg et al. 1994; see also Goldberg 1995), weak definites do not share all the characteristics of those collocations most commonly referred to as idiomatic. Like idioms, the particular identity of the noun is critical to accessing the enriched meaning. Unlike idioms, however, the noun's regular meaning contributes to the whole: there is some hospital involved in (5) and some radio in (6), whereas for an idiom like let the cat out of the bag, there is neither a cat nor a bag involved. Furthermore, unlike idioms, synonymous contextual words in weak definite phrases often can be interchanged while preserving the enriched and non-unique interpretation, as in example (8), where took the bus, rode the bus and caught the bus all allow weak interpretations. In contrast, this is not typically true for idioms, as is illustrated in example (9). The idiomatic interpretation of bit the bullet is not available for the related verbs nibbled and chewed.

(8) Jed took/rode/caught the bus.

(9) Roxy bit/nibbled/chewed the bullet.

This holds not only for opaque idioms like those just mentioned, but extends to those with some degree of compositionality, like "take the lead" or "make a face" (AmEng; BE "pull a face"). The sense of "drop the matter" ("stop talking about it") does not survive in "release the matter" nor in "drop the thing".

Although weak reference is incompatible with restrictive modification, weak definites can have certain types of modifiers in them nonetheless, unlike most idioms (Aguilar-Guevera and Schulpen, 2012). This class of definites has further characteristics. In languages with singular/plural marking, generally only one form, usually but not always the singular, allows for such an interpretation. Plural forms are possible, as in (go to) "the movies", (do) "the dishes", or (be from) "the sticks" (i.e. a remote, rural place). They are not found (normally) in subject position, even of passivized sentences.

Perhaps their most salient semantics diagnostic, apart from non-unique reference, is their "semantic enrichment". There is typically a certain amount 
of "extra meaning" associated with weak readings, in contrast to the regular definite readings. Consider the examples of (10):

a. Going to the store is going to a store and more...(shopping)

b. Being in the hospital is being in a hospital, and more...(healing)

c. Looking at the calendar is looking at a calendar, and more... (gathering information)

The type of semantic enrichment depends upon the collocation, but in cases such as the above it amounts to something like "using the object for its customary purpose", with a degree of habituality of action normally implied.

It is noted in Carlson and Sussman (2005) and Carlson (2006) that all the characteristics above, save the singular/plural distinction, are also properties of a class of English bare singulars (Stvan 1999). Such a class of definite noun phrases with the same set of types of interpretations and restrictions can be identified in languages other than English, including the Romance and Celtic languages, and beyond, including possibly languages in which there is no definite article (e.g. Lee 2012).

In what follows, we will outline first a hypothesis about how these weak definites are to be accounted for in the syntax and semantics, and then we will present and discuss a series of experiments that are mostly based on that analysis to see where it leads us. We are not going to be dealing with the entire range of examples that Poesio notes. Schwarz (2009) presents an analysis that holds of the entire range, but he has trouble subsuming our class into his otherwise quite general analysis. We believe that this is because the "weak definites" we are examining require a special analysis that we present in the next section. After we present some experimental results, we then conclude with our view of where this leaves us.

\section{The "incorporation" analysis}

At present there is no consensus regarding a linguistic analysis that accounts for the presence of the definite article in the weak definite constructions we examine here. An account is presently being explored form a number of different perspectives (e.g. for one such account, see Schwarz 2012). Our strategy in this paper is not to argue that any of the proposals are incorrect (and ours, correct), but rather to inject more data derived from experimentation into the discussion, that may bear on the question of how best to analyze the construction (or, indeed, if there is any such "construction" at all). In order to do this, we will outline the rationale for adopting one analysis that seems to us to make a good deal of sense as a means of accounting for the types of data we have already encountered, but more importantly to serve as a guide in our experimental investigations. 
We begin by asking, if the definite article in a weak definite does not contribute something like uniqueness or familiarity (which we will take as so for the moment), what is it doing there? One immediate solution would be to treat the definite article as a syntactic marker in the case of these weak definites, without semantic import. It is inserted in order to satisfy some syntactic condition, devoid of semantic import. Vergnaud and Zubizarreta (1992) and Longobardi (1994) provide some precedent for this approach. Support for this view comes from the fact that weak definites often lexically alternate with a "bare singular" construction in English, yet the two constructions seem to mean almost exactly the same thing. For example, to be in jail without the article means almost the same thing as to be in the slammer (a colloquial term for prison), which has the definite article; neither phrase requires unique reference and both are used almost exclusively to describe convicts serving time, not simply people visiting or working in a prison. Moreover, whether a weak definite or a bare singular is used sometimes differs across dialects. In American English, to be in the hospital has the same meaning as the British English, to be in hospital. And for many speakers, the weak reading of on the television/radio/stage has the same meaning as to be on television/radio/stage. These observations are consistent with the hypothesis that the definite article contributes nothing to the meaning.

A second alternative, pursued by Aguilar-Guevara and colleagues (Aguilar-Guevara and Zwarts 2011), and one with some experimental support, is that the weak definite noun phrase is a generic NP, denoting a kind of thing and not an individual. This alternative treats the definite article as making its usual semantic contribution (or at least the one made in the case of definite generics), yet it does not result in any uniqueness of individual objects since the reference is generic. This also has the merit of predicting the correct form of the article used in weak definites in those languages where there is a bifurcation in the form of the definite article-use the one that the generic uses. This is the case in Fering, where the a-article (which we take to be the "weak" form-note its paradigm makes fewer distinctions than the d-article's does) is the one also used for generics.

A third alternative is that weak definites are parts of "incorporated" structures, at least in terms of their semantic composition, though it seems clearly not in terms of syntax/morphology. Mathieu (2006) presents such an analysis of certain constructions in French that are manifestly not incorporated grammatically. Incorporation, in languages where there is a syntactic/ morphological difference, is a process whereby two words in a phrasal grammatical relationship are fused to form a unit that has the status of a word (Baker 1986, 1998; Mithun 1984; see also Massam 2001). The most detailed studies have concerned verbs forming incorporated units with their objects and other arguments ("nounincorporation"), but prepositions may form units with their objects as well. In incorporated structures no articles appear; only the bare nominal form of the 
object is expressed. The semantics of noun-incorporation is fairly well described (Dayal 1999, 2011; Farkas and de Swart 2003; Chung and Ladusaw 2004; van Geenhoven 1998). There is general agreement that incorporated structures have the truth-conditional semantics of narrow-scope and usually number-neutral indefinites (being neither singular nor plural). There is also some precedent for attributing the semantics of incorporation to structures that do not create word units, as in "pseudo-incorporation" (Massam 2001; Dayal 2011) or in forms that appear similar to weak definites (Mathieu 2006). In likening our weak definites to incorporated structures, we are not taking the definite article to be a part of the incorporated structures themselves. As we will see below, rather, we will taking the role of the definite article to contribute its customary "weak" meaning, but at a place in the derivation that is "outside" the structure. So when we liken something like "take the bus" to an implicitly incorporated structure ("bus-take"), we are only concerned with the contributions of the combination of the lexical items themselves plus the contribution of the incorporated structure.

An incorporation framework that likens weak definite constructions to incorporated structures suggests an explanation for properties that appear characteristic of weak definites. Many grammarians have emphasized the implied "habituality" of the action expressed by an incorporated form (i.e., it is something of a type one usually does in the normal course of things); many also note that numerous incorporated forms give rise to what we will refer to as semantic enrichment or an enriched interpretation. The term semantic "enrichment" as we use it is inspired by Levinson's (2000) use of the term "pragmatic enrichment" to describe similar phenomena. A semantically enriched interpretation is viewed as a construction property, in the sense of Goldberg (1995), and for our purposes, helps characterize differences between the conventional meanings of the weak versus regular definites.

Consider the following example. To "kill reindeer" in Chukchee (Dunn, 1999) means what one expects, but the fused, incorporated form roughly equivalent to "reindeer-kill" means that one is killing reindeer as a part of food preparation, which is the most common purpose for killing the reindeer in that culture. Such semantic enrichment is commonplace in these structures, not just in Chuckchee but across most languages with the structure in it. While English obviously does not have incorporation in the formal morphological sense, we believe all of the described semantic characteristics attributed to incorporated forms are also attributable to weak definites. In other words, there is a reason to think that weak definites (and corresponding bare singulars) are interpreted as if they are formed from incorporated structures. This means that their key lexical items appear as constituents of the calculated meaning. For instance, take the train on its weak reading has train+take as a part of its meaning, which is interpreted as one would an incorporated form. 
An incorporation analysis also provides a potential explanation for why the definite article does not seem to make its customary contribution in these constructions. In particular, the semantic composition does not correspond to the surface syntactic composition. If we represent the meaning of the definite article as DEF and lexical items as their primed counterparts, a regular definite (e.g. "read the book") would to a first approximation have a syntax roughly like:

$$
\left[{ } _ { \mathrm { VP } } \text { read } \left[{ } _ { \mathrm { NP } } \left[{ }_{\mathrm{Art}} \text { the }\left[\left[_{\mathrm{N}} \text { book }\right]\right]\right.\right.\right.
$$

and have an interpretation as follows:

$\operatorname{read}^{\prime}\left(\operatorname{DEF}\left(\right.\right.$ book $\left.\left.^{\prime}\right)\right)$.

In contrast, a weak definite such as that occurring in the weak reading of "read the newspaper" would have a similar syntax,

$$
\left[{ }_{\mathrm{VP}} \text { read }\left[_{\mathrm{NP}}\left[_{\mathrm{Art}} \text { the }\left[_{\mathrm{N}} \text { newspaper }\right]\right]\right]\right.
$$

but a different compositional structure:

$\operatorname{DEF}\left(\operatorname{read}^{\prime}(\right.$ newspaper'))

This compositional structure appears unusual to say the least, a matter we return to below, but we believe it has several promising properties that capture salient features of weak definites. First, the noun phrase is no longer semantically definite; rather, the noun "newspaper" is combined directly with the verb, as it is in incorporation structures in languages where the combination of $\mathrm{N}$ and $\mathrm{V}$ is overt in the syntax/morphology. As mentioned earlier, the characteristic semantics of the object is that of a narrow-scope weak indefinite. And, we believe, this is an appropriate description of the truth-conditions of weak definites in English.

Second, since the V (or, the P in such cases as "(be) in the hospital") and the $\mathrm{N}$ form a constituent by themselves without intervening material, the formal dependency between them is more transparently stated than in a theory in which extra material is included. In English, in particular, it expresses the requirement that the two items must be adjacent.

Finally, while the definiteness is not associated with the NP, it is associated with the V-N (or P-N) combination. In this case, it expresses something like a "familiar" type of activity, one whose cultural currency is independently established and encoded in the grammar in this way-one already presumed known. This notion of "familiarity" is a commonly noted feature of incorporation in many languages. This does not mean, of course, that just any activity that is familiar to a given individual, or even large groups of individuals, is necessarily going to be expressed this way; instead, the language will encode some such familiar activities this way and it is only partially predictable which ones will be selected. We conceive of these structures as a an example 
of something corresponding to name creation - in this case the "naming" of "familiar" activities. This approach provides us with at the beginnings of a principled approach for understanding why the definite article may appear in some instances ("(be) in the slammer") but not in others ((be) "in jail"), as with proper names. The approach, like others, also predicts that it is the "weak" article, associated with names, that will be the form chosen in such cases as that of Fering. Which is again a correct prediction.

However, one is quite right to be skeptical of the analysis since it would require the definite article to combine not only with nominal meanings, but with (at least) PP and VP meanings as well. Consider, for instance, what an analysis of "go to the hospital" would be in the weak sense. The DEF would scope over the incorporated P-N form, roughly $\mathrm{DEF}\left(\left[_{\mathrm{PP}}\right.\right.$ to' $^{\prime}$-hospital'] $)$. However, the interpretation of this whole would still need to be the same semantic type as a regular directional PP, albeit it now one that carries the enrichment associated with the situation of receiving health care. This is necessary since the verb of directed motion can vary retaining the enrichment-one can travel to the hospital, walk, limp, crawl, bicycle, skate there (etc.), all in the weak sense. It is at present an unmet challenge to provide a detailed analysis of an article meaning that would be able to combine with nominals, PP's, and VP's and retain a single sense. However, the single notion of "(cultural) familiarity" makes it seem a promising venture. Also, in a way the incorporation analysis we are assuming makes it very hard to distinguish it from the "kinds" analysis discussed above. This is because the meaning of the incorporated bare nominal form is "generic" in the sense that it does not have the capacity for individual reference. So the issue for us is primarily the compositional role of the definite article, and not primarily about generic interpretations.

Finally, and as a footnote we will return to shortly, there are two plausible ways of describing the "incorporation" hypothesis her. One is that the definite article may scope over the V-N (or P-N) combination. Or, one could it is an article that may do so-which would include the possibility of indefinite articles playing a similar role.

\section{Experiments}

We now present a series of experiments, most of which are described in much more detail in Klein (2011) and in Klein et al. (2013). For our purposes we will only present the "bare bones" of the design, statistical analysis, and materials. While generally based on the "incorporation" account sketched above, the import of the conclusions is expected to affect anyone's analysis of the phenomenon. 


\section{Experiment 1.}

This is a "basic" experiment to make sure weak definites are experimentally distinguishable from regular definites. Experiment 1 examines whether weak definites carry the same uniqueness constraints as regular definite NPs. If so, we expect that in a situation where a particular referent matching the description has previously been introduced into the discourse, listeners should interpret the definite NP as referring to that object; if, on the other hand, weak definites do not refer uniquely, then listeners should be willing to interpret a weak definite NP as referring to another object matching the description that has not been previously introduced. We created situations in which we can infer participants' interpretations by asking them to act out scenarios by moving magnetic pictures around on a metal board.

Eighteen members of the University of Rochester community participated in the experiment for pay. Participants all had normal or corrected-tonormal vision and were native speakers of American English. Participants listened to scenarios containing both a first and second mention of either a weak definite or regular definite noun phrase, as in:

(11) Rudy is a very literary guy. Today he wrote in his diary.

Then, Rudy read the newspaper/book.

This afternoon, Patty read the newspaper/book too.

Twelve nouns with weak definite readings (e.g. newspaper) and readily depicted referents were chosen from examples in the literature. For each weak definite noun, a similar noun without a weak definite interpretation (e.g. book) was chosen as its regular definite match; twelve scenarios like those in (11) were created so that the critical noun could either be a weak definite noun, or a matched regular definite.

Scenarios were pre-recorded with a naïve male speaker who was instructed to maintain a naturalistic and non-contrastive prosody. The first part of each scenario referred to a distracter object in the visual display (e.g., diary in example (11)); the second part referred to the critical noun using a definite noun phrase; the third repeated that critical definite noun phrase. Participants were instructed to act out the narrated scenario as it unfolded by using magnetic images on the metal board. Following work by Brown-Schmidt and Tanenhaus $(2006,2008)$, which demonstrated that listeners assume that areas with visual boundaries are distinct referential domains, we created two implicit domains on our magnet boards by painting each half a different color. Each referential domain contained magnets with images of a person (a male on one side, and a female on the other), a non-identical token of a distracter object, and a non-identical token of the critical noun. For example, each character might have a different newspaper or book. Without this domain restriction, the task would have strongly favored the regular definite interpretation: nearly any 
noun phrase that can be interpreted as a weak definite can also be interpreted as a regular definite, and pilot results suggested that participants would have a strong bias to select and manipulate an object they had previously moved. Figure 1 shows a schematic version of the setup of the magnets and metal board.

Figure 1

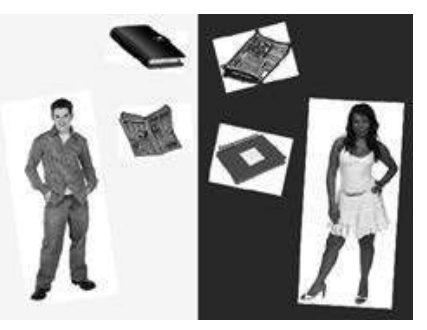

Our domain restriction design manipulation proved to be very strong; in pilot work, we found that participants were reluctant to cross domains by moving an object from, for example, the yellow (left) side of the magnet board to the blue (right) side of the board. Therefore, we included some fillers that required objects to cross domains. Participants were instructed to use the magnets to act out the narratives as they heard them. They were given three practice trials at the beginning of the experiment, and if they had no questions afterward, the experiment began immediately. Sessions were video recorded, so that subjects' actions could be coded and analyzed later.

Results. In 73 percent of the trials with weak definite noun phrases, participants selected the new token as the final referent, which corresponds to a nonunique interpretation of the definite phrase. In contrast, participants selected the new token only 34 percent of the time with regular definite noun phrases. The results are statistically significant.

Our results confirm the predicted difference between weak and regular definite noun phrases. By choosing the new token for weak definite noun phrases, participants indicated that they did not interpret the weak definite as requiring a unique referent. Instead, it seemed that participants preferred to replicate the event-type (e.g. doing newspaper-reading with whichever newspaper was present in the character's domain) rather than selecting one unique token to use throughout the enactment of the scenario (e.g. consistently manipulating a particular one of the two newspaper magnets). It was surprising, however, that participants selected the new token as frequently as they did for the regular definite noun phrases. The most likely explanation for the relatively high proportion of new tokens selected for regular definites is that the implicit domain restriction we created using the colored backgrounds was extremely effective; it discouraged our participants from crossing domains despite our efforts to encourage 
them to do so with our use of fillers. In post-experimental briefings, many participants reported that they felt hesitant to cross domains, even on those filler trials that left them with no other choice. Overall then, our results are consistent with the hypothesis that weak definites do not require a unique referent.

\section{Experiment 2.}

Experiment 2 examines the referential properties of weak definites using a task that does not depend on domain restriction. In a series of scene-verification judgments, participants were asked to rate the naturalness of a description for a picture that contained either two people involved in the same event with the same object (e.g., two characters riding a single bus) or two people involved in different events with distinct objects (e.g. two characters riding two different buses); we call these one- and two-token scenes, respectively. If weak definite noun phrases do not refer uniquely, two-token scenes should be judged to be more natural when paired with a description containing a weak definite than when paired with a description containing a regular definite. One-token scenes were included to rule out the possibility that effects were simply due to the plausibility or familiarity of the events (bus-riding versus bicycle-riding) and how they were depicted. We also compared the ratings of descriptions containing matched (singular) indefinites with those of descriptions containing regular and weak (singular) definites in a first attempt to tease apart the role that the definite and indefinite article might play in constructions that allow weak definite interpretations.

Thirty-three members of the University of Rochester community participated in this study for pay. All were native speakers of American English with normal or corrected-to- normal vision.

Experiment 2 used a $2 \times 2 \times 2$ design, crossing the number of tokens depicted in the scene (one or two) with the type of article (definite or indefinite) and with the type of noun (regular or weak). We will call the condition where a weak noun is expressed with the indefinite article a "weak indefinite." Descriptions were constructed using a conjoined noun phrase subject, as in (12) below:

Dean and Anne rode a/the bike/bus.

The descriptions were paired with illustrations that showed either one or two tokens of the critical noun (e.g. bike or bus). An example of each type is shown in the left-hand and right-hand panels of Figure 2.

Figure 2

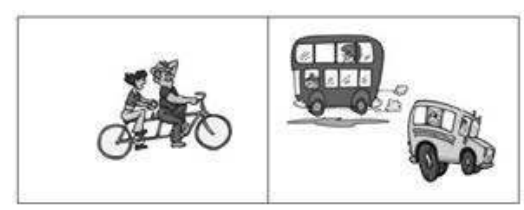


In the one-token conditions, we expect that all noun/article combinations should be rated highly; it is perfectly felicitous for a bike, the bike, a bus or the bus to describe a scene in which there is only one bike, or only one bus. It is in the two-token conditions that we anticipate differences will arise. Specifically, we predict that participants will rate two-token scenes as worse matches for regular definite descriptions. For example, Dean and Anne rode the bike is not an ideal description for a picture showing Dean and Anne each riding a distinct bicycle, since in such a scene, the definite noun phrase cannot refer uniquely. However, if weak definites, as we hypothesize, do not refer uniquely and appear to be number-neutral, weak definite sentences should be preferable matches for two-token scenes and thus rated higher, since the lack of a unique referent should not matter.

For the regular definite noun phrases, the indefinites serve as a check on the strength of the manipulation. We expect that for nouns that allow only a regular definite interpretation, indefinites would be rated as better matches than definites for two-token scenes, whereas no difference is predicted between indefinites and definites for nouns that allow weak reference. Fillers were constructed by creating sentence/scene pairs for which there was either a very clear semantic match, or a very clear mismatch.

Scenes and sentences were presented simultaneously on a computer monitor. Participants were instructed to rate the appropriateness of the written descriptions for each picture on a seven-point scale, with seven being the most appropriate. Participants were given three practice trials during which they could ask questions of the experimenter before beginning the actual experiment.

As expected, when only one token of the critical noun was pictured, all descriptions were rated as being highly appropriate (with averages of 6 or higher). For the two-token pictures, the ratings depended upon both noun type (weak or regular) and type of article (definite or indefinite). We found a significant three-way interaction between number of tokens, article type, and noun type $(\beta=-0.46, S E=0.15, p<0.01)$. The three-way interaction arises because effects of article type and noun type arise only in the two-token pictures.

We then conducted analyses using only trials with two tokens pictured. As anticipated, regular nouns received lower naturalness ratings than weak definites; the weak definite noun phrases (e.g. rode the bus) received the highest average acceptability rating (mean rating $=4.82$ ). Weak indefinites (e.g. rode $a$ bus) were rated only slightly lower than weak definites (mean rating $=4.71$ ), and still lower were regular indefinites (e.g. rode a bike) (mean rating $=4.24)$, with regular definites (e.g. rode the bike) being least acceptable (mean rating $=$ 3.67. Overall, our results indicate that nouns allowing weak reference are generally more acceptable with two-token pictures than nouns that do not allow such an interpretation, and that this difference is greater among definite than indefinite noun phrases. Regular definites are significantly less acceptable with these scenes than regular indefinites are; however, this is not true for weak 
nouns, where definites are numerically, but not statistically, better than indefinites for describing two-token scenes.

Our results provide further support for the hypothesis that weak definites do not refer uniquely in the way that regular definites do. But the results for the indefinites paint a more complex picture. Weak indefinites are rated as slightly more acceptable with two referents than are regular indefinites and they are given ratings similar to those of weak definites. When the noun can take a weak reading, it does not seem to matter much (for this task) whether the noun phrase is definite or indefinite. Recall that one of the novel predictions of the incorporation analysis is that even when paired with an indefinite article, nouns that allow for a weak definite interpretation might be preferentially interpreted as evoking an event of a conventional sort rather than an individual. That is, in the sentence Jerome and Sandy rode a bus, the activity of bus-riding rather than any specific bus-entity may be evoked (if there are actually "weak indefinites" alongside "weak definites"), in much the same way that corresponding weak definite NP's (e.g. the bus) appear not to uniquely refer. We further explore the relationship between weak definites and weak indefinites in Experiment 3.

\section{Experiment 3.}

The results from Experiments 1 and 2 provide support for the hypothesis that weak definite NP's do not uniquely refer to token objects. This is consistent also with a kind-referring approach as well, where enrichment is also provided for. The results do not directly address the question of what interpretations comprehenders assign to weak definite NP's. One hypothesis, which is consistent with Experiments 1 and 2, is that weak definite constructions (not the weak definite NP's themselves) describe an event or activity type, which would rule out the possibility of having as a constituent part an individual discourse referent (then it would not be a type of appropriate generality). As a result, weak definite constructions convey information associated with that activity. When we say someone is in the hospital, we seem to convey not only that they are physically located in a hospital, but also that they are there getting medical treatment. In fact, the most colloquial weak definites (such as the slammer (i.e., prison) in (13)) show enrichment so salient that it becomes difficult to cancel or override the enriched interpretation, as demonstrated in the contrast between (13a) and (13b). In (13a), which is completely felicitous, the second clause is consistent with the enriched interpretation (i.e., serving time). In contrast, (13b), where the second clause strongly favors a regular definite reading, is distinctly odd:

(13) a. The plumber was in the slammer, because he didn't pay his taxes.

b. The plumber was in the slammer, because a pipe burst in cellblock 4 . 
Experiment 3 explicitly tests the enrichment hypothesis by building on this observation to examine whether the conventional associations of an event, such as going to the hospital to get medical treatment, will override the specific properties normally associated with agents, such as the mailman delivering mail.

With regard to weak definite constructions, there appear to be two main categories of enrichment involved: some (e.g.play the piano, read the newspaper, walk the dog) seem to convey that the activity is a commonly exercised activity, while others, particularly the ones denoting destinations (e.g. (go) to the store, (be) at the store, (go) to the hospital, (be) in the hospital, etc.) express enrichment related to the typical service received at that location. We chose to restrict our efforts to this latter set of weak definites for practical reasons: scenarios in which people visit a destination for a non-canonical reason are more plausible than similar scenarios for regularly exercised-activity weak definites. For example, a mailman going to a store to deliver mail rather than to shop is not odd in the way that a person taking out the trash to show it off to the neighbors (and not for the sake of disposal) is odd. For our items, we chose agents with strongly associated prototypical activities (e.g., mailman, cab driver, pizza guy, etc.), as in (14).

The FedEx driver had to go to the farm/hospital.

In (14), when the destination is a regular definite (the farm) we might infer that the FedEx driver was making a delivery to the farm (making deliveries is a typical activity for a FedEx driver). But if, as we hypothesize, weak definites serve to introduce semantically enriched meanings related to conventional events associated with the noun, when the driver's destination is a weak definite noun phrase (such as the hospital), comprehenders might instead infer that the FedEx driver needed medical treatment and was not making a delivery to the hospital. In this way, weak definites might influence what listeners understand such sentences to represent: listeners' assumptions based on the agent might be overridden by the enriched meanings of weak definites, which could in turn affect the underlying mental representation of a described event. Experiment 3a. Eighteen members of the University of Rochester community participated in the experiment for pay. All were native speakers of American English. Experiment 3a compared weak definites and regular definites in an interview-style task, in which participants were asked about their interpretations of sentences like the one in (14). Our experimental items were constructed by pairing a random noun/subject from a list of agents that have well-known prototypical activities with a random destination goal from a list of weak definite places. A matched regular definite destination was chosen to be the basis of comparison for the weak definites.

Participants were seated at one computer within the lab, and a research assistant, who served as the "interviewer," was seated at another computer. The participant and the interviewer were able to see and talk to each other, 
but could not see each other's screens. Participants were instructed to read the sentences presented to them on their computer screen and visualize the scene that the sentence described. The interviewer then asked the participant a yes/ no question to establish whether or not the participant had imagined a scene in which the agent of the sentence was engaging in their prototypical agentive role. The interviewer recorded each yes/no answer as it was given. The interviewer then asked the participant to describe the scene she had imagine. An example trial is presented in (15):

Text on Screen: The Fed Ex driver had to go to the farm/hospital.

RA: Was the Fed Ex driver making a delivery in the scene you imagined?

[Subject responds yes or no.]

RA: Describe the scene you imagined.

[Participant responds by describing the scene in her own words.]

This set-up allowed us to assess whether the use of a weak definite as the destination would result in an enriched reading that "cancelled out" inferences about the typical activities of the agent. That is, we could examine whether delivering packages or getting medical treatment emerged as the stronger inference.

Results. Participants were more likely to answer "no" (indicating they did not imagine the agent engaging in his or her prototypical activity) when they read sentences with weak definites than when they read sentences with regular definites (71\% "no" responses vs 40\% "no" responses).

Our results demonstrate that after reading a sentence containing a weak definite destination, participants were more likely to say that the agent was not performing their conventional role or prototypical activity in the scene they imagined, and after reading a sentence containing a regular definite, they were more likely to say that the agent was performing their conventional role. This pattern is consistent with the hypothesis that weak definites evoke a canonical activity type, and that this enrichment often overrides event biases that may be conveyed by the sentence's agent.

The descriptions given by participants provide further evidence that enrichment drives the difference in "yes" and "no" responses between weak definites and regular definites. For example, our annotations of the responses indicated that when participants answer "no" to the direct question asked in (11), they almost always give descriptions in which some typical motivation for the activity of hospital-going is mentioned (i.e., "the driver got sick", "the driver hurt himself"); these responses were most common with weak definite destination nouns. "Yes" responses in our data are almost always associated with descriptions in which typical associations with the agent are mentioned (i.e., "the driver had to make a delivery", "the driver was dropping off a package"); such responses were more likely to occur when the destination noun did not allow a weak interpretation, such as the farm. 
Experiment 3b. Recall that the incorporation framework predicts that there should also be weak indefinite noun phrases. If that is the case then, nouns that can take a weak definite interpretation are also more likely to be interpreted in an enriched manner when paired with the indefinite article. Experiment $3 b$ examines the interpretations of weak indefinites by using the same method as was used in Experiment 3a.

Sixteen members of the University of Rochester community participated in the experiment for pay. All were native speakers of American English. Experiment $3 \mathrm{~b}$ used the same design and materials as Experiment 3a, except that the definite article in each item was replaced with the indefinite article.

We see a similar pattern of results for Experiment $3 b$ as we did in Experiment 3a; overall, participants gave more "no" responses with weak indefinites than with regular indefinites $(71.1 \%$ and $49 \%$ "no" responses, respectively). These results are strong but marginally significant $(\mathrm{p}<0.06)$. However, when we combine the results from Experiment $3 \mathrm{a}$ and $3 \mathrm{~b}$ and analyze them in the same fashion, with article type (either definite or indefinite) as an additional fixed effect, we do not find a significant interaction between noun phrasetype and article-type.

So, when participants read a sentence with a "weak indefinite" (i.e. an indefinite article but a noun that can host a weak reading in the definite), they were more likely to say that the agent was not performing their canonical role in the scene they imagined. This is consistent with the idea that these weak nouns might be preferentially interpreted as conveying an enriched meaning, even when paired with the indefinite article. The descriptions given by participants also lend support to this idea, since they show the same pattern as in Experiment 3a: when the participant responds with "no" to the direct question, he or she almost always includes information in their description relating to the activity associated with the destination noun, just as in Experiment $3 \mathrm{a}$. We also did a follow-up experiment to address some potential criticisms in this experiment. It showed the same results.

\section{Experiment 4.}

The incorporation framework allows for the prediction that nouns that appear in weak definite phrases also have weak indefinite readings in the same sentential contexts, and the data from Experiment 3b, and to a lesser extent Experiment 2, support this hypothesis. The typical reading of a definite noun phrase expresses a property involving some uniquely identified individual and thus clearly differs from the typical reading of an indefinite noun phrase. The weak reading of definites, however, is truth-conditionally very similar to that of a regular indefinite. What then, if anything, does the definite article contribute to the meaning of a weak definite? 
We pointed out earlier that if the weak construction has something close to the semantics of a regular indefinite, it begins to look like the definite article is contributing nothing, or else (perhaps) contributes the value of an indefinite to the NP instead. However, the incorporation hypothesis suggests that definite and indefinite articles make their normal contributions if we assume that the compositional structure is ARTICLE(V(N)). That is, the semantic effect of the article depends upon the content of the incorporated interpretation, including relevant contextual material, and not just the interpretation of the noun.

As noted earlier, it is generally agreed that definiteness has the semantic effect of making reference to either discourse-old or unique or "familiar" entities (Heim 1982; Kadmon 1999; Roberts 2003) and that indefinites introduce new and "unfamiliar" entities. So, on this account is not the train that is familiar (or unfamiliar), but rather the action of train-taking that is taken to be already known. On this view, the distinction between take the train and take a train should then reduce to a subtle one: whether the instance of train-taking is implied to be a "familiar" instance (such as something one does regularly) or an "unfamiliar" instance (that is, a train-taking that is outside one's familiar habitual realm). Experiment 4 was designed to provide a preliminary test of this hypothesis by probing to see whether we could elicit a familiarity difference between weak definites and indefinites with nouns that can host weak readings in the definite.

Twenty-four naive adult speakers of English volunteered to participate in the study for payment via Amazon Mechanical Turk. We created scenarios in which two different locations were established for a fictional "speaker," with one location being their usual or home location, and another being a location they visited less frequently. In the final sentence of each scenario, this speaking-character in a text-based narrative uttered either a weak definite or its indefinite counterpart, as in the following example:

Kent lives in coastal North Carolina with his parents. One of his favorite pastimes is collecting seashells, and he picks them up whenever he has the chance. Twice a year, the family travels to coastal Florida to visit his grandparents.

Kent wrote an email to his friend, saying: "I went to the beach last weekend." Where do you think he was? [Listed along a scale from the less to the more familiar location.]

1. Definitely in Florida

2. Probably in Florida

3. Maybe in Florida

4. Probably in North Carolina

5. Definitely in North Carolina

If instead he had written, "I went to a beach last weekend." Would he be:

1. More likely to be in Florida

2. Less likely to be in Florida 
In order to provide a concrete test we make the assumption that in a familiar location, activity would be more familiar. Participants were asked to give their interpretation of Kent's "utterance" using a 5-point rating scale, and similarly for the remaining materials. They were then presented with a version of the sentence with the determiner switched and asked whether this alternate sentence conveyed that the speaker was more or less likely to be in his secondary location. This final two-alternative forced-choice "switch" question allowed us to probe participants' intuitions about the distinction in meaning conveyed by the definite versus the indefinite article when used in a weak construction.

Results. We find a significant difference in responses to the first question depending on whether the initial utterance contained a definite weak construction or its indefinite counterpart: the mean rating for initial weak definites was 3.7 , whereas the mean rating for initial weak indefinites was 3.1, indicating that the weak definite was rated as denoting the activity in the more familiar, or primary, location. Among responses to the second "switch" question, we also find a significant difference between those scenarios in which the switch was from a weak definite to a weak indefinite, and those in which the switch was from a weak indefinite to a weak definite. In the former case, participants chose " 1 " (the answer corresponding to being more likely to be in their less usual location) $85 \%$ of the time, while in the latter case, participants chose " 1 " only $35 \%$ of the time. In other words, a shift from an indefinite to a definite was interpreted as indicating the protagonist was more likely to be in the familiar location, whereas a shift from a definite to an indefinite was interpreted as indicating that the protagonist was more likely to be in a less familiar location.

Weak definites and weak indefinites differed in familiarity. Taken together, these data suggest that participants intuit that the use of the definite article in a weak definite noun phrase conveys an element of expectedness or familiarity, while the use of an indefinite article with the same noun conveys a lack of familiarity or typicality which pertains to the greater context of occurrence rather than the activity type itself. This indicates that at least some aspects of meaning typically conveyed by the definite article are maintained in weak definite noun phrases, and that while both weak definites and weak indefinites convey similar enriched meanings centered on conventional events or activities, they evoke subtly different interpretations related to the standard semantics of the definite and the indefinite article.

\section{Conclusion}

The experimental results clearly indicate that behavioral measures can distinguish the two classes of interpretations. In all this, recall that nearly any weakly-interpreted NP may also have a perfectly legitimate and plausible regular reading as well: in using weak definites we were never assured that subjects would necessarily select that reading. Nonetheless, it appears that on many, 
possibly most occasions, they did. The results reported are suggestive of the "incorporation" view insofar as the analysis highlights the event-type, but it does not rule out other analyses which attribute definiteness to the NP that also allow for a conventional event-type reading. The result that seems more compelling is the possibility of there being weak indefinites alongside weak definites. Obviously, a lot more work needs to be done to determine what exactly is going on with indefinites. The strongest hypothesis is that there really are "incorporated" indefinites alongside the "incorporated" weak definites, but it does not readily give an account of why the results found in Experiment 3 are attenuated vis-à-vis the definites. It could be that the weak indefinites and regular indefinites have such similar truth-conditional interpretations, that it is difficult to tell them apart and hence they interfere with one another in judgment tasks in a way that the definites do not, being more easily intuitively distinguished in their interpretations. Or, it could conceivably be that the weak definite structure interferes with weak indefinites in judgment-formulation, and is an epiphenomenal effect. Our Experiment 4 suggests that this is not the case, but clearly more work and more data, of all sorts, is welcome in trying to achieve clarity.

\section{REFERENCES}

Aguilar-Guevara, Ana; Zwarts, Joost (2011). Weak definites and reference to kinds. In Li, N. \& Lutz, D. (eds.), Proceedings of SALT 20: 179-196. Cornell University, Ithaca, NY: CLC Publications.

Aguilar-Guevara, Ana; Schulpen, Maartje (2012). Modified weak definites. Paper presented at the conference on "(IN)Definites and Weak Referentiality", Florianapolis, Brazil. August, 2012.

BAKER, Mark C. (1988). Incorporation: A Theory of Grammatical Function Changing. Chicago: University of Chicago Press.

BAKer, Mark C. (1996). The Polysynthesis Parameter. Oxford: Oxford University Press.

BARKer, Chris (2005). Possessive weak definites. In Kim, J.; Lander, Y. \& Partee, B. (eds.), Possessives and Beyond: Semantics and Syntax: 89-113. Amherst, MA: GLSA Publications.

Brown-Schmidt, Sarah; TANenhaus, Michael (2006). Watching the eyes when talking about size: An investigation of message formulation and utterance planning. Journal of Memory and Language 54/4: 592-609.

Brown-Schmidt, Sarah; Tanenhaus, Michael (2008). Real-time investigation of referential domains in unscripted conversation: a targeted language game approach. Cognitive Science 32/4: 643-684.

CARlson, Greg; Sussman, Rachel (2005). Seemingly indefinite definites. In Kepsar, S \& Reis, M. (eds.), Linguistic Evidence: Empirical, theoretical, and computational perspectives: 71-86. Berlin: de Gruyter. 
Carlson, Greg; Sussman, Rachel; Klein, Natalie; Tanenhaus, Michael (2005). Weak definite NPs. In Davis, C.; Deal, A \& Zabbal, Y. (eds.), Proceedings of NELS 36: 179-196. Amherst, MA: GLSA Publications.

Chung, Sandra; Ladusaw, William (2004). Restriction and Saturation. Cambridge, MA: MIT Press.

DAYAL, Veneeta (1999). Bare NPs, reference to kinds, and incorporation. In Matthews, T. \& Strolovitch, D. (eds.), Proceedings of SALT 9: 34-51. Cornell University, Ithaca, NY: CLC Publications.

DaYal, Veneeta (2011). Hindi pseudo incorporation. Natural Language and Linguistic Theory 29/1: 123-167.

Dunn, Michael (1999). A Grammar of Chukchi. Doctoral dissertation, Australian National University.

Eberhard, Kathleen; Spivey-Knowlton, Michael; Sedivy, John; TAnenhaus, Michael (1995). Eye-movements as a window into spoken language comprehension in natural contexts. Journal of Psycholinguistic Research 24/6: 409-436.

EBert, Karen H. (1971). Referenz, Sprechsituation und die bestimmten Artikel in einem nordfriesischen Dialekt (No. 4). Bredstedt: Nordfriisk Instituut.

FARKAS, Donka; DE SwART, Henriette (2003). The Semantics of Incorporation. Chicago: CSLI.

GoldBerg, Adele E. (1995). Constructions: A Construction Grammar Approach to Argument Structure. Chicago: The University of Chicago Press.

Hartmann, Dietrich (1982). Deixis and anaphora in German dialects: the semantics and pragmatics of two definite articles in dialectal varieties. In Weissenborn, J. \& Klein, W. (eds.), Here and There: Cross-linguistic Studies on Deixis and Demonstration: 187-207. Amsterdam: John Benjamins.

HeIm, Irene (1982). The Semantics of Definite and Indefinite Noun Phrases. Doctoral dissertation, University of Massachusetts.

KADMON, Nirit (1990). Uniqueness. Linguistics and Philosophy 13/3: 273-324.

KLeIn, Natalie (2011). Convention and Cognition: Weak Definite Noun Phrases. Doctoral dissertation, University of Rochester.

Klein, Natalie; GegG-Harrison, Whitney; Carlson, Greg; Tanenhaus, Michael (2013). Experimental investigations of weak definite and weak indefinite noun phrases. Cognition 128/2: 187-213.

LeE, Hae-Yun (2012). Definiteness effects in korean numeral classifier constructions. Paper presented at the conference on "(IN)Definites and Weak Referentiality", Florianapolis, Brazil. August, 2012.

LÖBNER, Sebastian (1985). Definites. Journal of Semantics 4/4: 279-326.

LONGOBARDI, Giuseppe (1994). Reference and proper names: a theory of N-movement in syntax and logical form. Linguistic Inquiry 25: 609-665.

Massam, Diane (2001). Pseudo noun incorporation in Niuean. Natural Language and Linguistic Theory 19/1: 153-197.

Mathieu, Eric (2006). Bare nouns and morpho-syntactic reflexes of semantic incorporation: some new facts. In Bateman, L. \& Ussery, C. (eds.), Proceedings of the ThirtyFifth Annual Meeting of the North East Linguistic Society : 403-418. Amherst, MA: GLSA Publications.

Mithun, Marianne (1984). The evolution of noun incorporation. Language 60/4: 847-894.

Nunberg, Geoffroy; SAG, Ivan A.; WAsow, Thomas (1994). Idioms. Language 70/3: 491538. 
Poesio, Massimo (1994). Weak definites. In Harvey, M. \& Santelmann, L. (eds.), Proceedings of the Fourth Conference on Semantics and Linguistic Theory: 282-299. Cornell University, Ithaca, NY: CLC Publications.

RoBerts, Craige (2003). Uniqueness in definite noun phrases. Linguistics and Philosophy 26: $287-350$.

Schwarz, Florian (2009). Two Types of Definites in Natural Language. Doctoral dissertation, University of Massachusetts, Amherst.

SchwARz, Florian (2012). How weak and how definite are weak definites? Ms., University of Pennsylvania.

Stvan, Laurel S. (1998). The Semantics and Pragmatics of Bare Singular Noun Phrases. Doctoral dissertation, Northwestern University.

Van Geenhoven, Veerle (1998). Semantic Incorporation and Indefinite Descriptions: Semantic and Syntactic Aspects of Noun Incorporation in West Greenlandic. Stanford, CA: CSLI Publications.

Vergnaud, Jean-Roger; Zubizarreta, Maria Luisa (1992). The definite determiner and the inalienable constructions in French and in English. Linguistic Inquiry 23/4: 595-652.

\section{RÉSUMÉ}

De façon typique, les groupes nominaux définis réfèrent à une entité identifiable et unique, appartenant au common ground du locuteur et de l'interlocuteur. Cependant, certains groupes nominaux définis (comme l'hôpital dans Marie est allée à l'hôpital et Jean aussi) semblent violer la contrainte d'unicité. Nous présentons une série d'expériences qui portent sur cette classe de définis. Nous considérons très attentivement l'hypothèse selon laquelle les interprétations « faibles » apparaissent dans des constructions implicitement « incorporées » et nous tentons de donner un début d'explication pour motiver cette hypothèse et mesurer ses conséquences. Nos expériences montrent que, comparés aux définis standard, les définis faibles n'ont pas besoin de référer de façon unique et sont très facilement associés à une lecture enrichie sémantiquement qui entre en concurrence avec les inférences normales qu'on pourrait tirer d'une telle phrase. Le résultat sans doute le plus surprenant de nos expériences est que les noms pouvant donner lieu à des lectures faibles semblent conserver certaines des propriétés caractéristiques des lectures faibles, même quand ils sont utilisés dans des groupes nominaux indéfinis. Nous essayons d'expliquer cela en termes d'incorporation.

\section{Mots-CLÉS}

Article défini, incorporation, défini faible, référence faible, sémantique, pragmatique. 